\title{
Validation of the calculation of a wooden column with a support unit on glued steel plates
}

\author{
Igor Rudnev ${ }^{l^{*}}$, Viktor Zhadanov ${ }^{2}$, and Vladimir Garipov ${ }^{3}$ \\ ${ }^{1}$ Candidate of Technical Sciences, Associate Professor of the Department of Building Structures, \\ Orenburg State University. Russian Federation, 460018, Orenburg, ave. Victory, 13. \\ ${ }^{2}$ Head of the Department of Building Structures, Orenburg State University. Russian Federation, \\ 460018, Orenburg, ave. Victory, 13. \\ ${ }^{3}$ Candidate of Technical Sciences, Associate Professor of the Department of Construction Production \\ Technology, Orenburg State University. Russian Federation, 460018, Orenburg, ave. Victory, 13
}

\begin{abstract}
The article proposes a structural solution for the base of a wooden frame column on flat links glued in the support part of the column - steel plates welded to the base plate. The results of numerical studies of the column, taking into account the parameters of the adhesive connection of the plates with wood and the anisotropy of wood, are presented. The column model takes into account the geometric and physico-mechanical characteristics of wood, steel plate bonds and adhesive compound. The main results of numerical studies are verified with the results of the analytical calculation of the column performed by the method of initial parameters. A physical model with the proposed structural solution of the column base was made and tested. The numerical and analytical calculations of the column were validated, and the main conclusions of the experimental and theoretical study were presented.
\end{abstract}

\section{Introduction}

The main advantages of wooden housing construction are the excellent thermal insulation and environmental properties of load-bearing and enclosing structures and the short construction time of objects with a high degree of factory readiness. One of the directions of development of wooden housing construction is the construction, including frame and frame-panel buildings (figure 1). Increasing the volume of construction of buildings with a wooden frame involves improving the nodes of the wooden frame between themselves and the mating structures.

\footnotetext{
* Corresponding author: ru403@mail.ru
} 


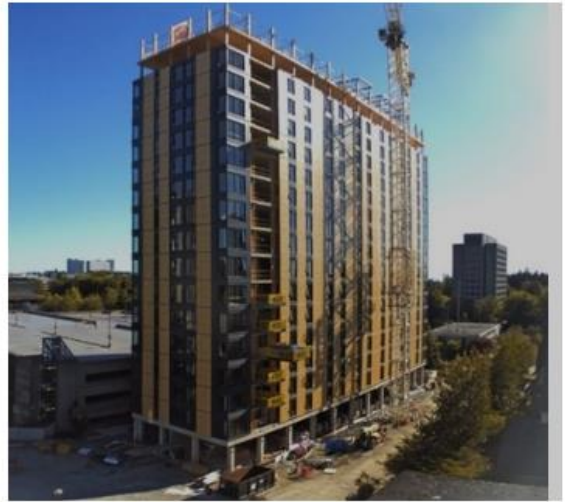

a)

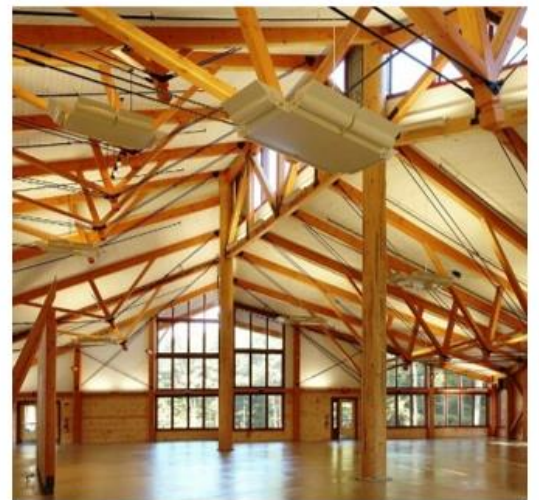

b)

Fig. 1. Wood frame buildings: a) Student residence in Canada; b) Interior of the Hayden Camp dining hall, USA, owned by the Fresh Air Fund's.

One of the promising directions for the development of structural solutions of nodes is the use of glued plates as rigid connections. In particular, the works [1,2] present the results of research and development of adhesive joints of steel plates with wood and nodes working on pulling-indentation. There is no information in the scientific and technical literature about experimental and theoretical researches of such compounds, including those that work on bending. At the same time, the use of flat rods in the adhesive joints of wooden structures that experience bending deformations opens up great prospects for the construction of components of frame buildings.

Figure 1 schematically shows the structural solution of the base of a wooden column on steel plates glued into the wood, working on compression with bending.

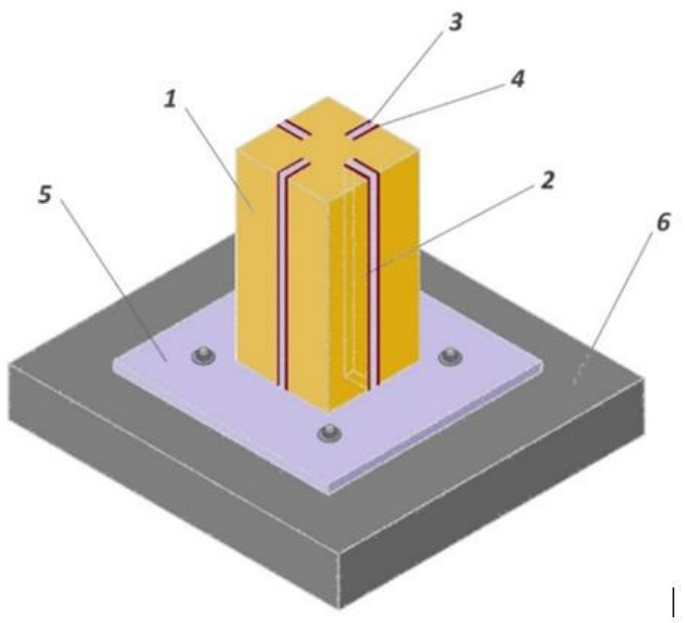

1 - column of solid wood; 2 - milled grooves; 3 - glued steel plates; 4 -adhesive compound; 5 base plate; 6 - column foundation.

Fig. 2. Schematic drawing of the support unit of a wooden column on steel plates glued into the wood. 
The joint is made by gluing into the symmetrical grooves (2) selected in the support area of the wooden column (1), steel plates (3) welded to the base plate (5) of the column attachment to the foundation (6). The surface of the steel plates is prepared to improve the adhesion of the adhesive compound (4) with metal and wood [3].

The experimental study of the connections of elements with the use of glued steel plates as connections is quite time-consuming. One of the options for reducing the complexity of developing design solutions for typical parametric nodes is the validation of previously verified numerical studies $[4,5]$, on the basis of which, among other things, simplified engineering methods for designing connections are developed. The relevance of the proposed research is determined, firstly, by the development of new design solutions for nodal joints based on the use of glued plates, and secondly, by the creation of a base of experimentally confirmed numerical models for testing the methods of engineering calculation of joints. The purpose of this work is to verify the reliability of the analytical and numerical calculation of the adhesive nodal joint by the finite element method based on a comparison with the results of an experimental study. The main tasks of the study include the creation of a computer finite element model and the calculation of the stress-strain state of a wooden column structure with a support node on glued steel plates in the elastic area, its verification and validation of the numerical model based on the recommendations of regulatory documents $[6,7]$.

\section{Methods}

To solve this problem, at the first stage, a finite element plate-rod model of a wooden fourfloored frame-panel building of a postgraduate dormitory of Orenburg State University with a grid of columns of $3 \times 5$ meters was calculated in the APM Civil Engineering software complex (Korolev, Russia). According to the results of the calculation (fig. 2a) the most loaded column (the column of the ground floor) was identified and a computer model of the column with a cross section of $150 \times 150 \mathrm{~mm}$ was created in the same software package (fig. 2b).

The coupling of the final elements of the adhesive compound "steel-adhesive composition" and "adhesive composition-wood" is assumed to be rigid. The adequacy of such modeling of the adhesive joint was previously confirmed in [8,9]. The upper part of the column is defined by the rod finite elements because there is no need to detail the calculation of this part of the column and reduce the dimension of the problem. The coupling of the lower node of the rod end element of the column with the upper layer of the nodes of the bulk finite elements of the support part is performed using absolutely rigid rod elements.

In the upper part, at a distance of $1.6 \mathrm{~m}$ from the base plate, the model is loaded with a transverse force, the maximum value of which is 10 times higher than the value of the bending moment that occurs in an off-center loaded column of the basement of a fourfloored wooden frame. No compressive force was applied to the column model. The reduced force value, as well as the geometric parameters of the most loaded column, are preliminarily determined by the calculation of the building frame.

The boundary conditions are modeled by the imposition of prohibitions on the movement and rotation in all directions of the steel plate nodes and the prohibition of vertical movements of the nodes of the compressed part of the wooden bar located on the lower face of the bulk finite elements of the column, which corresponds to the actual design solution in the form of welding the plates to the base plate and resting the compressed part of the bar in the base plate during compression with bending. 


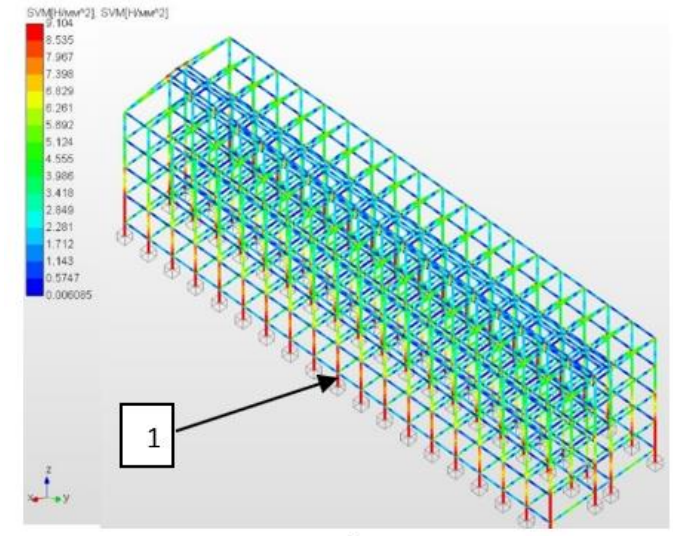

a)

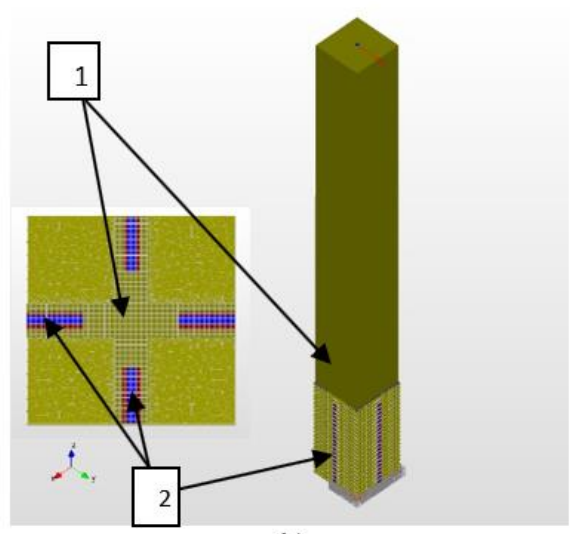

b)

1 - the beam of the most loaded column; 2 - glued steel plates of the support part.

Fig. 3. Stress map in the rod finite element model of the building frame (a) and the finite element model of the most loaded column (b).

The material of the glued plates is low-carbon steel with a modulus of normal elasticity of the first kind equal to $200,000 \mathrm{MPa}$, a Poisson's ratio equal to 0.3 , a shear modulus equal to $81,000 \mathrm{MPa}$, and a calculated tensile resistance of $255 \mathrm{MPa}$. The material of the beam is grade 2 pine wood with a modulus of elasticity along the fibers equal to $10,000 \mathrm{MPa}$, a modulus of elasticity across the fibers - $400 \mathrm{MPa}$, a Poisson's ratio across the fibers (stresses along the fibers)-0.45, a Poisson's ratio along the fibers (stresses across the fibers) - 0.018, a shear modulus along and across the fibers - $500 \mathrm{MPa}$, a calculated tensile resistance along the fibers $-10 \mathrm{MPa}$, a calculated compression resistance along the fibers $14 \mathrm{MPa}$, a calculated resistance to local chipping along the fibers in adhesive connections in $2.1 \mathrm{MPa}$. The adhesive compound has an elastic modulus of $3000 \mathrm{MPa}$, a Poisson's ratio of 0.17 , a shear modulus of $1250 \mathrm{MPa}$, and a design resistance of $70 \mathrm{MPa}$.

At the second stage of the study, an analytical calculation of a pinched rod loaded with a transverse force was performed as a verification calculation. In this case, the theory of cross-bending of composite beams can be applied, fig. $4 \mathrm{a}, \mathrm{b}$.

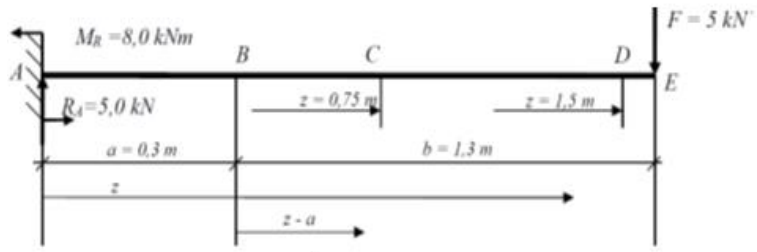

a)

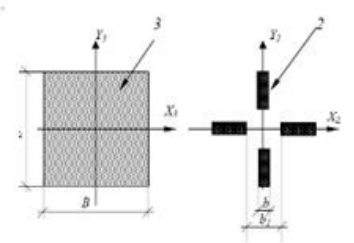

b)

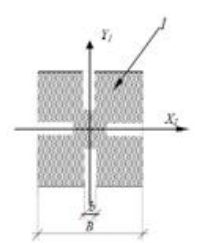

Fig. 4. Design model of a column, reduced to a beam, (a) and column section types (b).

Since the effect of the transverse force on the curvature is small, in general, you can use the basic differential equation of an elastic line and determine the desired deflections (displacements) using the method of initial parameters, which allows you to reduce the solution to finding only two constants - the deflection and the angle of rotation at the 
origin. The equations of the method of initial parameters for deflections and angles of rotation of sections, applied to the loading scheme (in fig. 4), will be written as follows:

$$
\begin{gathered}
E I_{x} y^{\prime \prime}=M_{x} ; \\
E I_{x} \theta(z)=\frac{R_{A} \times z^{2}}{2}-\frac{M_{R} \times z^{1}}{1}+\frac{R_{A} \times(z-a)^{2}}{2}-\frac{M_{R} \times(z-a)^{1}}{1}+C ; \\
E I_{x} y(z)=\frac{R_{A} \times z^{3}}{6}-\frac{M_{R} \times z^{2}}{2}+\frac{R_{A} \times(z-a)^{3}}{6}-\frac{M_{R} \times(z-a)^{2}}{2}+C z+D .
\end{gathered}
$$

The initial parameters are determined from the boundary conditions: $\mathrm{z}=0, \mathrm{y}_{\mathrm{A}}=0=\mathrm{D}=0$; $\mathrm{z}=0, \theta_{\mathrm{A}}=0 \Rightarrow \mathrm{C}=0$.

In the final form, for the entire beam, we obtain the following deflection equation:

$$
E I_{x} y(z)=\frac{R_{A} \times z^{3}}{6}-\frac{M_{R} \times z^{2}}{2}+\frac{R_{A} \times(z-a)^{3}}{6}-\frac{M_{R} \times(z-a)^{2}}{2} .
$$

Due to the fact that in the section $\mathrm{AB}$ along the length of the beam, the rigidity is provided by the physical, mechanical and geometric characteristics of the sections made of two materials - wood and steel (the rigidity of the adhesive compound is neglected due to the insignificant thickness of the layer), it is possible to apply the principle of independence of the action of forces. The calculation of deflections in the $\mathrm{AB}$ section (movements of point B) is performed separately for two types of calculated sections (fig. 3b, types 1, 2), followed by summing up the calculation results.

The deflection equation for the entire beam in this case will have the following form:

$$
\begin{array}{r}
y(z)=\frac{R_{A} \times z^{3}}{6 E_{1} I_{x}^{1}}+\frac{R_{A} \times z^{3}}{6 E_{2} I_{x}^{2}}-\frac{R_{A} \times(z-a)^{3}}{6 E_{1} I_{x}^{1}}-\frac{R_{A} \times(z-a)^{3}}{6 E_{2} I_{x}^{2}}-\frac{M_{R} \times z^{2}}{2 E_{1} I_{x}^{1}}- \\
-\frac{M_{R} \times z^{2}}{2 E_{2} I_{x}^{2}}+\frac{M_{R} \times(z-a)^{2}}{2 E_{1} I_{x}^{1}}+\frac{M_{R} \times(z-a)^{2}}{2 E_{2} I_{x}^{2}}+\frac{R_{A} \times(z-a)^{3}}{6 E_{3} I_{x}^{3}}-\frac{M_{R} \times(z-a)^{2}}{2 E_{3} I_{x}^{3}} .
\end{array}
$$

The moment of inertia of the cross sections of the three types I3, I2, I1, shown in FIG. 4, was determined by the known formulas:

$$
\begin{gathered}
I_{x}^{3}=\frac{B^{4}}{12}, \\
I_{x}^{2}=\frac{b \times B^{3}+(B-b) \times b^{3}}{12}-\frac{b \times\left(B-b_{1}\right)^{3}+\left(b_{1}-b\right) \times b^{3}}{12}, \\
I_{x}^{1}=I_{x}^{3}-I_{x}^{2} .
\end{gathered}
$$

The calculation takes into account the physical and mechanical characteristics of the materials introduced in the finite element model of the compound. In addition, in the section "A", the stress that occurs at the base of the glued plates is analytically determined, provided that they are firmly fixed to the column base plate. The absence of contact of the column wood with the base plate is assumed conditionally, that is, the type of section 2 , shown in fig. $4 \mathrm{~b}$, is adopted as the section that perceives the bending moment from the force.

The maximum voltage is determined by the following formula: 


$$
\sigma=\frac{M_{x}}{W_{x}}=\frac{F \times L}{\frac{I_{x}^{2}}{y_{\max }}},
$$

where: $L$ is the force shoulder; $I_{x}^{2}$ is the moment of inertia of the section of the second type; $y_{\max }=\frac{B}{2}$ is the distance from the center of gravity of the section to the most distant bent fiber.

At the third stage, to validate the obtained calculation results, the column was tested on a laboratory stand, fig. 5. The plate of the support unit, made with the use of steel plates glued into the bar, is attached to the frame of the stand with four anchor bolts. The loading of the column was carried out by a threaded jack, the force from which is transmitted via a cable to a thrust pin with a hook installed in a through hole in the upper part of the column. The amount of force was controlled by a model tensile dynamometer with an accuracy of $0.8 \mathrm{kgf}$. The values of the displacements (deviations of the column from the vertical) were determined in three sections along the length of the column. To do this, a stand with rods for attaching indicators was mounted on the stand. In sections "C", "D", 4 hour-type indicators were installed with a division price of $0.01 \mathrm{~mm}$ (two indicators on each side of the bar). In the "B" section, 6 indicators were installed, including two electronic indicators on both sides of the column with a division price of $0.001 \mathrm{~mm}$ to fix the movements of the glued plate relative to the bar.

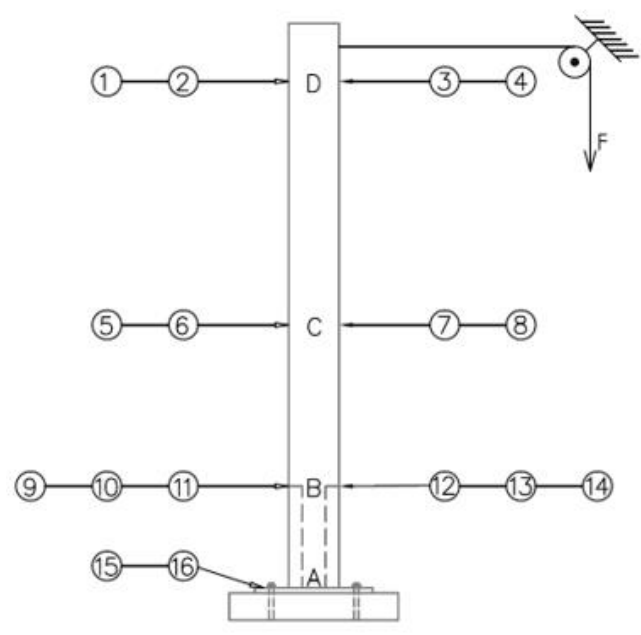

a)

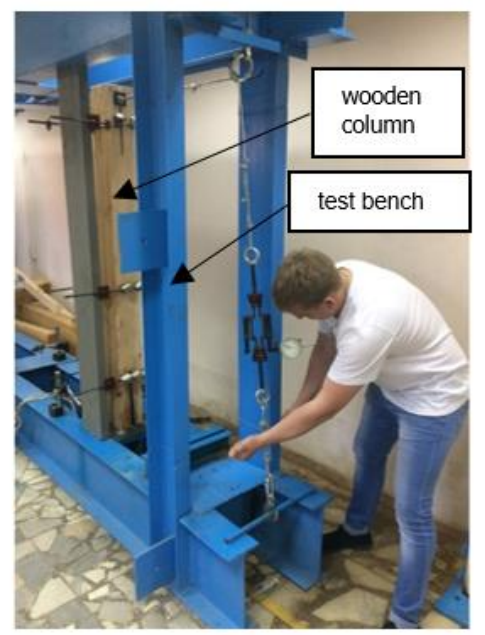

b)

$1 \div 16$ - indicators for determining movements

Fig. 5. A diagram with the location of the indicators (a) and a photo of the laboratory installation (b) at the time of fixing the load equal to $500 \mathrm{kgf}$.

The loading of the column was carried out up to $500 \mathrm{kgf}$ in stages after $100 \mathrm{kgf}$, with a time delay of 5 minutes and subsequent unloading according to a similar scheme. The actual cross-section movements given in the Results section were determined as the arithmetic mean of the indicator readings. 


\section{Results}

The values of the main controlled parameters based on the results of the experiment, analytical and finite element calculations are summarized in Table 2.

Table 2. Verification and Validation matrix

\begin{tabular}{|l|c|c|c|c|}
\hline \multicolumn{2}{|c|}{$\begin{array}{c}\text { Parameters of the stress-strain } \\
\text { state }\end{array}$} & $\begin{array}{c}\text { Finite element } \\
\text { model }\end{array}$ & $\begin{array}{c}\text { Analytical } \\
\text { calculation }\end{array}$ & $\begin{array}{c}\text { Results of the } \\
\text { experiment }\end{array}$ \\
\hline \multirow{4}{*}{$\begin{array}{l}\text { Displacement of the } \\
\text { cross section "A" at } \\
\text { a load F equal to: }\end{array}$} & $100 \mathrm{kgf}$ & $2,42 \mathrm{~mm}$ & $2,38 \mathrm{~mm}$ & 0 \\
\cline { 2 - 5 } & $200 \mathrm{kgf}$ & $4,82 \mathrm{~mm}$ & $4,78 \mathrm{~mm}$ & $4,90 \mathrm{~mm}$ \\
\cline { 2 - 5 } & $300 \mathrm{kgf}$ & $7,22 \mathrm{~mm}$ & $7,18 \mathrm{~mm}$ & $7,51 \mathrm{~mm}$ \\
\cline { 2 - 5 } & $500 \mathrm{kgf}$ & $9,63 \mathrm{~mm}$ & $9,58 \mathrm{~mm}$ & $10,12 \mathrm{~mm}$ \\
\hline Equivalent plate stresses (max) & $12,04 \mathrm{~mm}$ & $12,00 \mathrm{~mm}$ & $13,00 \mathrm{~mm}$ \\
\hline & $243,4 \mathrm{MPa}$ & $236,8 \mathrm{MPa}$ & $\begin{array}{c}\text { No plastic } \\
\text { deformation of steel } \\
\text { and destruction of } \\
\text { welds }\end{array}$ \\
\hline $\begin{array}{l}\text { Equivalent stresses } \\
\text { in wood, (max) }\end{array}$ & $12,27 \mathrm{MPa}$ & - & $\begin{array}{c}\text { No destruction of } \\
\text { wood }\end{array}$ \\
\hline
\end{tabular}

Fig. 6 shows the results of calculations and experimental measurements of the displacements of three sections of the column under the action of a transverse force of 500 kgf.

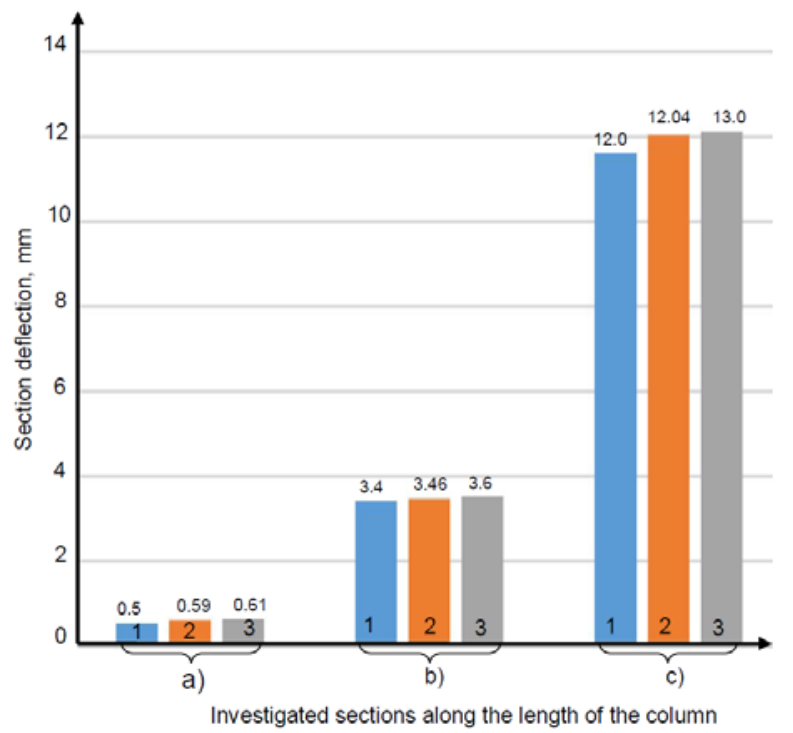

1 - the results of the analytical calculation; 2 - the results of the finite element calculation; 3 - the results of the experiment.

a) - displacement of the "B" section; b) - displacement of the "C" section; c) - displacement of the "D" section.

Fig. 6. - Comparison of column cross-section displacement values. 


\section{Discussion}

The authors believe that the conducted numerical and experimental studies have generally confirmed the technical feasibility and feasibility of using glued flat steel ties in the nodes of wooden frames experiencing bending deformations. This is evidenced by the following facts:

- the maximum stresses in the plates in the welding zone with the column base plate do not exceed the design resistance of the steel $255 \mathrm{MPa}$;

- the maximum stresses in the wood do not exceed the calculated bending resistance of the wood at $14 \mathrm{MPa}$;

- the structure operates in an elastic area when the column is loaded with a bending moment 10 times higher than the calculated moment acting on the column in the building frame, in the absence of compressive stresses;

- the absence of any defects caused by the impact of the transverse force that creates the maximum bending moment at the site of the adhesive connection of the plates with the wood.

\section{Conclusions}

According to the resulting matrix of verification and validation of the linear static analysis of the stress-strain state of a wooden column with a support node on glued steel plates, the following conclusions should be given:

1) the discrepancy between the results of the analytical and numerical calculation of the horizontal displacements of the column sections is not more than $2 \%$. In this case, the values of the displacements calculated analytically are less than the values obtained by the finite element method. This fact is explained by the fact that, in the analytical model, the rigidity of the support unit of the column is increased due to the adoption of boundary conditions in the form of a rigid seal for both steel plates and timber;

2) for the same reason, the equivalent stresses in steel plates are more significant in the finite element calculation when the values differ by no more than $2.9 \%$;

3 ) the experimental data corresponded to the results of numerical calculations with a difference between the theoretical and experimental values not exceeding $5 \%$.

The conducted validation of the adhesive joint showed that, by analogy with the calculation method of the universal node of the "TSNIISK» system [10], the method of engineering design of joints of wooden elements on steel plates glued into wood can be reasonably worked out using the results of finite element calculations. This approach will significantly reduce the time required to identify dependencies, correlations, and multi-factor analysis of the stress-strain state of wooden structural units.

The work was carried out on an initiative basis without attracting funding from third-party organizations.

\section{References}

1. Rudnev I. V. Pulling out steel plates glued into the wood. Analytical calculation and experiment / Rudnev I. V., Zhadanov V. I. // Bulletin of the I. Ya. Yakovlev Chuvash State Pedagogical University. Series: Limit State Mechanics. - Cheboksary: 3, p. 109121

2. Rudnev I. V. Method for calculating the connections of elements of wooden structures on glued steel plates / Rudnev I. V., Zhadanov V. I. // Bulletin of the Orenburg State University. - Orenburg: pp $182-191$ 
3. Nodal prefabricated and collapsible connection of wooden rods [Electronic resource] / Lisitsky I. I., Zhadanov V. I., Rudnev I. V., Arkaev M. A., Lisov S. V.; patentee of the Federal State Budget. educated. institution of higher Prof. education "Orenburg State University".- No. 2016140285yu-Byul. No. 29. - 2017. - 2 p.

4. Modzhtaba A., Akimov P. A., Msakhalaya Zh. I., Sidorov V. N., Kaytukov T. B. On the issue of verification and multi-level approaches to the local calculation of building structures. Part 1. Part 2 International Journal for Computational Civil and Structural Engineering Volume 12, Issue 4, pp 41-79

5. Rudnev I. V. Verification and validation of finite-elemental calculation of wooden structures connections on gluedflat steel rods [Electronic resource] / I. V. Rudnev, V. I. Zhadanov, M. M. Sobolev, D. A. Ukrainchenko // IOP Conference Series: Materials Science and Engineering : VII International Symposium Actual Problems of Computational Simulation in Civil Engineering, 1-8 Jul. 2018, Novosibirsk / IOP. Electronic data. - Novosibirsk, Russian Federation : IOP Publishing Ltd,2018. - Vol. 456, conf. 1. - P. 1-7. - 7 c.

6. GOST R 57700.10-2018 Numerical modeling of physical processes. Determination of the stress-strain state. Verification and validation of numerical models of complex structural elements in the elastic domain

7. NAFEMS QSS 0012015 Engineering modeling. Quality management systems. Requirements

8. Vodiannikov, M. A., \& Kashevarova, G. G. (2017). Numerical and experimental modeling of the rigid joint of layered wooden structures. International Journal for Computational Civil and Structural Engineering, 13(2), 84-92.

9. V. A. Zhilkin. Numerical study of the stress-strain state of adhesive joints of wood and steel plates of variable thickness / News of higher educational institutions. Construction. - Novosibirsk: 5, pp. 5-13

10. Turkovsky S. B. Glued wooden structures with nodes on glued rods in modern construction (TSNIISK system) / Turkovsky S. B., Pogoreltsev A. A., Preobrazhenskaya I. P.// - M.: RIF "Stroymaterialy", 308 p. 